\title{
Periodical indexes on the edge of time A look at the introduction to library research course at Juniata College
}

A llow me to begin with a confession: I always wanted to be a science ction writer, hence the title. In fact, I incorporate science ction short stories into the one-credit Introduction to Library Research course I teach every semester. Not only does the assignment expose the students to our extensive special collections (in this case, the Loyal F. Ramsey Science Fiction Collection), but it also helps to ground a course whose content is largely electronically based in the material, printed world that is the foundation of libraries. While so many of us librarians and students alike become more and more entangled in the immediacy of electronic information, it is important to remember the lasting value of the printed artifact itself, and several assignments throughout the semester emphasize that point.

In this semester-long introduction to the rigorous world of library research, I have always included a hands-on assignment involving our collection of print indexes. Fifteen years ago, when the course began, these print indexes were still indispensable, as computers often failed us at the time. Have these unwieldy behemoths of the periodical publishing world now been relegated to the dusty, and perhaps musty, back shelves of your library somewhere between the Twilight Zone and Rigel 7? With the advent of online databases and thousands of full-text journals, periodical indexes have almost surely been buried under the omnipresent avalanche of technology; we have dropped our subscriptions to most of them over the years.

It is important to keep in mind the shortcomings of the technology inundation, however; while the depth of online coverage is increasing every day, most databases still lack comprehensive coverage of published periodicals from the early 19th and 20th centuries.

\section{The Big Picture}

As a small, liberal arts college, Juniata College tries to emphasize the Big Picture in most of what we teach; it is dif cult to imagine any kind of picture, regardless of size, being fully complete after looking solely at electronic databases, which are still a relatively small representation of the human intellectual record. Libraries are preservers and conservators of this record, and it is increasingly incumbent upon us as librarians to make sure our students recognize that EBSCO and ProQuest are not technological panaceas. Sometimes, students still have to get their hands dirty.

I begin the print index assignment with the following introduction:

You are in a time machine, and the year is 1990. We are still the Juniata Indians (now Eagles). The library has two computers, and one of those does not work. The only way you can really do research is to look up books in the card catalog, and look up journal articles (today's assignment) in the print indexes in the basement. (You have to blow the dust off them first). Your

Mary Murray is head of instruction, e-mail: murraym@juniata.edu, and John Mumford is library director, e-mail: mumford@juniata.edu, at Juniata College in Huntingdon, Pennsylvania

๑ 2008 Mary Murray and John Mumford 
paper is due in three days, so you must research the following topics and determine if we own any of the journals in which the articles were published. Can you find the article in the library? You ask someone for full-text online, and by the perplexed look you get, you realize it does not yet exist! Use our electronic journal list to determine if we own the articles!

The Introduction to Library Research course has proven to be good launching pad for teaching students how to search for articles in the old-fashioned way. While all students receive cursory information literacy instruction and an introduction to databases during their freshman year, it is rare that we get the chance to involve students in in-depth, old-school research that is the hallmark of the mythical College Library. This assignment, however, is a chance to push students out of their technological comfort zone.

The guided worksheet that accompanies the assignment asks students to look for articles in our collection of print indexes from The London Times to the Book Review Index. They are given subjects to research, then they must select the most appropriate periodical index for each subject, nd an article about that subject, and write out the complete citation of that article. The exercise calls on multiple higher-end research skills: Students must rst identify an appropriate index, then they must perform subject searching through the pages (without the help of an electronic index), identify individual articles (while realizing that almost every periodical index cites articles in a different format), and decipher the various pieces of article citations in order to try to locate the articles in our library. (The citation-writing exercise is valuable in and of itself; as many of us know, it is not always a given that the students will know the difference between the article title and the journal name.)

The second part of the assignment does become electronic, as the students have to gure out if we have access to the journals that contain the articles they have found. Not only must students realize that they have to search in the periodical list for the journal name (not the article title, as so many try to do), but along the way their confusion is also compounded by guring out which part of the citation is the journal name, title of article, and author s name, and what those abbreviations for illustrated or containing bibliography really mean. By the end of the exercise, the exasperated but relieved students have experienced what students went through years ago and perhaps have a better understanding of the fundamental construction of indexes and databases. As an added bene $t$, they must ask a lot of questions throughout the process.

Because of the unfamiliarity and relative intricacy of the assignment, it is a tough exercise, particularly for the 8:00 a.m. sections. But it always seems to be worthwhile to step back to a time when researching was all tactile and hands-on. While completing this activity, the students soon realize that in the days before computer-assisted searching, one had to dig to nd information.

\section{What students gained}

Some appreciation for the old ways of research is not the only lesson gained with this assignment. Students also begin to reach an understanding of the construction of a database. By working with a physical manifestation of an electronic database, they can see that the results they get with a computer search are not just random pieces of freeoating information adrift like space nebulae, but that the electronic databases themselves have the same underlying foundations citations, subject headings, journal, and article titles that they see in the print index. The indexes become a tool for teaching students not just how to nd information, but also how information has to be organized in order for it to be found. There is a certain amount of value as well in the inevitable trial-and-error process the students go through as they complete the assignment the process of searching and struggling, battling through see also 
references, having to take time and skim through the headings, even in some cases having to look up information in an index that refers to an abstract in another volume, are all worthwhile endeavors. The repetition and the struggle can be valuable tools for teaching students about the complexity of research understanding how a .13-second Google (or ProQuest) search is rarely the starting and stopping point for nding information. In a way, hands-on research can be a building block, much like hitting the tackling dummy or juggling a soccer ball.

All librarians place a great amount of value in the hands-on approach to student learning, and we are no different. Most of the lessons in the class are hands-on, with very short lectures and occasional interruptions to the students work to make sure they are on the right track. The physical approach to learning not only teaches the students that they need guidance and must ask questions, but it also complements the auditory and visual learning that is taking place by attaching a tactile element to the learning experience. Many students need the reinforcement of learning by doing in order to grasp a concept fully. It is one thing to tell students how a print index works, but quite another thing to place an index in their hands and offer guidance as they try to gure it out for themselves. Often, the physical act of paging through an index reinforces many of the more abstract concepts we try to teach throughout the semester. The trial, error, and initial confusion are all part of the learning process.

\section{What librarians learn}

Teaching this course has consistently taught me that students do not always understand what we consider to be obvious. It is easy to take for granted what we think they know, but working with the students one-on-one with complicated assignments allows us to see where we need to be more explicit in our instruction. Particularly in the case of this assignment, we assume that most students know that information is still available in print, that they know that journal publishing in print far predates the Internet revolution, that they know how an index (of any kind) works. Sometimes, going back to the basics is the most ef cient way to impart knowledge. Having the students operate, even for just an hour, almost entirely in the world of print materials is a valuable exercise in itself for demonstrating the dizzying breadth of published information and for showing students some fundamental tenets of information classi cation the stuff that frequently gets hidden beneath the slick graphics and interfaces of today s electronic indexes. How much are the students able to take advantage of this growing database world without some kind of understanding of the tools that laid the groundwork?

In keeping with the old-school theme (who reads books in a library, anyway?), we emphasize hands-on experience with physical books in other lessons, as well. As mentioned previously, one week is devoted to having students read a science ction short story from our science ction special collections and write a review of it, students also spend two weeks lost on an Extreme Treasure Hunt in our reference collection, and another week is spent analyzing a rare book from our archives. Often we become so busy in a library, what with endless printing and electronic database searching, that we forget to read, experience, and appreciate such things. These tactile reinforcements serve as another reminder of the forebears of today $\mathrm{s}$ information world; they also jolt students into cognizance by prying them away from the computer in front of which they spend so many hours of their days.

In teaching these students about the relative obscurities of library research, we learn a lot about what they nd to be confusing and what we take for granted that they already know. By watching the students learn, we become better teachers and have a better framework for working with other students not just in the library classroom, but even at the reference desk and across campus. The students have found, too, a certain amount (continues on page 702) 
It should be stressed that SERU is not a one-size- ts-all approach. Because the SERU statements are intended to articulate common (but not necessarily universal) practices, they will not t every circumstance. Instead, SERU is intended as an alternative to license agreements when such an alternative makes sense to both parties to a transaction.

Some parties may not be comfortable dealing in high-cost or high-risk transactions without a license agreement, while others may be required by their general counsel to negotiate licenses for all purchases, no matter the cost or perceived risk. If either party is uncomfortable with using the SERU approach (or should either party seek to make changes to the SERU), then a negotiated license may be more appropriate to complete the transaction. The SERU FAQ provides additional suggestions as to how SERU may be implemented. ${ }^{4}$

\section{Implementing SERU}

As noted earlier, SERU was adopted as a NISO Recommended Best Practice early in 2008. The SERU statements of practice are available at the NISO Web site. ${ }^{5}$ This site also provides many other resources, including an FAQ, links to relevant articles that provide more detail on SERU, and details on the aforementioned SERU Registry as well as instructions for joining a electronic list devoted to discussion, advice, and information about SERU.

The rst step toward implementing SERU is to determine whether such an approach would work for your institution or company by reading through the statements, FAQ, and associated articles and presentations linked from NISO s SERU page. If applicable, join the SERU Registry and discussion list.

Publishers should let potential customers know if they would prefer to use SERU instead of a license agreement for a given transaction, and librarians should ask publishers if SERU could be invoked when engaged in preliminary discussions. If either party is unfamiliar with the SERU approach, they should be directed to the appropriate documentation at NISO s Web site. Through using SERU, both publishers and librarians may be able to sidestep the laborious licensing process, thereby freeing up valuable time and reducing the high costs associated with license negotiations.

\section{Notes}

1. Maria Collins, SERU: An Alternative to Licensing An Interview with Selden Durgom Lamoureaux, Serials Review 33:2 (June 2007), 12228.

2. Karla Hahn, SERU (Shared Electronic Resource Understanding): Opening Up New Possibilities for Electronic Resource Transactions, D-Lib Magazine 13:11/12 (November/December 2007), www.dlib.org/dlib /november07/hahn/11hahn.html.

3. See www.niso.org/publications/rp /RP-7-2008.pdf.

4. SERU FAQ can be found at www.niso. org/workrooms/seru/statementFAQ/.

5. NISO Web site is at WwW.niso.org /workrooms/seru. «

(Periodical indexes . . ." continued from page 676)

of charm in these kitschy and seemingly outdated activities; it s such a drastic change of pace for many of them that they respond reasonably well to the assignments, and many even get legitimately excited about the idea of holding in their hands a book that is hundreds of years old, or seeing a citation to an article that was published before their grandparents were born.

In a course that meets only once a week for one hour at a time, it is important to incorporate activities that have maximum impact. Nudging the students into the unfamiliar galaxy of print indexes is an example of one such activity. Not only are the students physically engaged in a tactile and unfamiliar learning environment, but the activity also provides students with a new lens through which they can understand modern information principles even from the edge of time. $n$ 